\title{
Police as Alert Responders? \\ Lessons Learned about Perceived Roles and Responses from Pretrial GPS Supervision of Domestic Violence Defendants
}

\author{
Jeremy G. Carter, Ph.D. ${ }^{1}$ \\ Eric Grommon, Ph.D. \\ School of Public and Environmental Affairs \\ Indiana University - Purdue University Indianapolis
}

\begin{abstract}
There is a substantial body of literature that examines police practices, behavioral responses, and victim cooperation when the police respond to intimate partner or domestic violence (IPV/DV) incidents. Less scholarly attention is given to the complex justice system response to IPV/DV incidents in which the police are one of many collaborative actors. A critical time in IPV/DV justice system processing is the period of time after arrest and before court disposition. Increasingly, the supervision of defendants in this pretrial period has been facilitated with the use of technology that creates new roles for the police. The present study seeks to explore perceived police roles and responses through an in-depth case study of a city-county municipality employing global positioning system (GPS) pretrial supervision of IPV/DV defendants. Using interview data from pretrial probation officers, victim advocates, and victims of IPV/DV, this research offers lessons learned and police practice recommendations for working as a unified systems front to curtail IPV/DV crimes and improve communication between multiple justice system stakeholders.
\end{abstract}

Keywords: Intimate partner violence, Domestic violence, Police response, Pretrial supervision, GPS monitoring

\section{Citation:}

Carter, J. G. \& Grommon, E. (2016). Police as alert responders? Lessons learned about perceived police roles and responses from pretrial GPS supervision of domestic violence defendants. Policing: A Journal of Policy and Practice. DOI: 10.1093/police/paw009

\section{Link:}

http://policing.oxfordjournals.org/content/early/2016/05/05/police.paw009.short?rss=1

\footnotetext{
${ }^{1}$ Corresponding Author: carterjg@iupui.edu
}

This is the author's manuscript of the article published in final edited form as: Carter, J. G., \& Grommon, E. (2016). Police as Alert Responders? Lessons Learned about Perceived Roles and Responses from Pretrial GPS Supervision of Domestic Violence Defendants. Policing, paw009. http://doi.org/10.1093/police/paw009 


\section{Police as Alert Responders? \\ Lessons Learned about Perceived Roles and Responses from Pretrial GPS Supervision of Domestic Violence Defendants}

\section{Introduction}

The use of global positioning system (GPS) technology to supervise intimate partner violence (IPV) and domestic violence (DV) defendants holds promise as a tool to deter contact between a defendant and a victim and reduce the potential for repeat victimization. While research examining GPS supervision of offenders has recently gained momentum, there remains little knowledge pertaining to the collaborative role of the police in a complex IPV/DV environment that necessitates interagency partnerships between police and community corrections agencies. It has been estimated that IPV/DV calls consume more police time than investigations of murder, rape, and aggravated assault combined in the United States (Nietzel, 2000). In the United Kingdom, police receive a call for service related to an IPV/DV incident every minute (Stanko, 2001). Despite these resource allocations and potential risks, research at the intersection of police and IPV/DV to date has largely focused on factors influencing victims' willingness to cooperate with, and report incidents to, the police as well as the effect of police reports and evidence on prosecutorial decisions of IPV/DV cases. Significantly less scholarly attention has been given to the role of the police as information providers who influence criminal justice system processing such as bond and pretrial supervision decisions. Moreover, police play a critical response role in referring victims to available resources, enforcing protection orders, responding to victim welfare checks made by supervising pretrial probation officers, and apprehending defendants for active warrants and new offenses during pretrial.

The present research presents the results of a case study comprised of in-depth interviews with pretrial probation officers, victim advocates, and victims of IPV/DV incidents in the United States and addresses the role of police as one component of a broader interagency criminal justice system response to incidents of IPV/DV. Study participants have provided unique perspectives regarding their 
experiences with police and their expectations of police roles in a pretrial setting where GPS supervision is used to monitor high-risk defendants. In an era where the monitoring of offenders with GPS technology has rapidly expanded across the United States and has gained momentum in the United Kingdom, Spain, and Latin America (Cotter and De Lint, 2009; Ibarra et al., 2014; Paterson and Clamp, 2014), these perspectives generate insights as to how police can be leveraged to create new, or enhance existing, criminal justice responses to IPV/DV offenses. This study seeks to broaden knowledge on perceived police roles and responses in managing IPV/DV crimes, contribute to ongoing discussions of best practice for police and criminal justice system processing, and advance an agenda for future research focused on the extended roles of the police during and after IPV/DV encounters.

\section{Review of Literature}

Context of Intimate Partner and Domestic Violence

IPV/DV represents a worldwide risk to victims and tends to disproportionately affect the health and safety of women. A 2005 multi-country study by the World Health Organization illustrated the wide-ranging health effects and violence experienced by women around the world (World Health Organization, 2005). Approximately 1.3 million women and 835,000 men are annually victims of physical assault from an intimate partners (National Institute of Justice, 2015). The nature of IPV/DV crimes, in and of themselves, make it difficult for victims to report the violence experienced. Victims are often exposed to greater risk of repeat violence after reporting IPV/DV to law enforcement (Erez et al., 2012; Tjaden and Thoennes, 2000). Evidence suggests that in certain domestic violence cases, arresting the offender or primary aggressor may only expose the victim to additional abuse (Sherman and Berk, 1984; Han, 2003). Moreover, women who attempt to separate from their abuser also find themselves at increased risk of violence (Block, 2003; Erez et al., 2012; Mahoney, 1991) and this type of defensive action has also been identified as an important risk factor for lethal violence and injurious outcomes (Campbell, 1995; Campbell et al., 2003; Logan and Walker, 2004; McFarlane et al., 1999). 
Ninety-five percent of women exiting violent relationships continued to experience psychological abuse while 39 percent experienced continued physical violence after separating (Hotton, 2001).

A wealth of evidence indicates victims of IPV/DV are continually exposed to further victimization and that the risk of such victimization is heightened following arrest. Such evidence highlights the salience of formal mechanisms intended to safeguard IPV/DV victims from continued abuse, such as mandatory protection orders and GPS or electronic monitoring of IPV/DV defendants and offenders. Moreover, this evidence emphasizes the importance of appropriate pretrial criminal justice interventions immediately following an IPV/DV incident when victims are most vulnerable and defendants may be released from jail while they await case disposition.

Police Response to Intimate Partner and Domestic Violence

The role of police as agents of formal intervention in response to incidents of IPV/DV in the United States can largely be attributed to the seminal work of Sherman and Berk (1984) in their Minneapolis Domestic Violence Experiment. Preceding this landmark experiment, IPV/DV was considered to be a family issue handled informally without intervention from the criminal justice system (Fagan, 1996; Finn et al., 2004). In the wake of the Minneapolis experiment, numerous jurisdictions enacted mandatory arrest policies (Frye et al., 2007; Hirschel et al., 2007). These policies rely on discretionary decision making on behalf of the responding officer. In such cases, police must assess characteristics of the incident as well as a variety of risk factors that may attribute to continued victimization if an intervention is not taken (Lee and Hoover, 2013). These risk factors include the victim's level of fear, defendant's aggressive behaviors, physicality of the assault, police awareness of previous incidents between the victim and defendant, the presence of substance abuse, and the presence of a protective order (Houry et al., 2004; Trujillo and Ross, 2008).

In their study of 501 police officers, Trujillo and Ross (2008) concluded that police awareness of a previous incident between the parties and the victim's level of fear were most influential in making 
a decision to take formal action. While a history of past IPV/DV incidents has been noted by other scholars as being a key factor leading to an arrest (Houry et al., 2004; Lorber and O’Leary, 2004), decisions informed by police perceptions of victim fear have been controversial. Nevertheless, victim fear is an important signal of risk and its use among service providers to inform resource allocations and safety planning strategies can validate its use with the police (Campbell, 2004).

Decisions to make an arrest are the product of individual decision-making nested within state statute, local ordinances, and departmental policy and practice. The initial responsibility of officers responding to IPV/DV incidents are associated with generating information about the incident and assessing the information that has been gathered. In an effort to partially standardize the information to be processed, IPV/DV risk assessment tools have been employed by law enforcement and criminal justice agencies across the country. These tools integrate many of the risk factors previously mentioned and overlap to a variable degree with assessments made by officers before arrest decisions.

\section{Role of Police as Integrators of Risk Assessment Tools}

IPV/DV risk assessment tools employ metrics of static and dynamic risk factors that are correlated with future assaults between intimate partners (Dutton and Kropp, 2000). Such tools are utilized to identify defendants who may be at greater risk of recidivism or failure to appear in court as well as maximize efficiency with limited resources (Andrews and Bonta, 1998). The predictive validity of these tools continues to be refined and has increased over time (Messing et al., 2015; Messing and Thaller, 2013). Consistent shortcomings of these risk instruments include failure to accurately collect the required information and the perception of criminal justice personnel that such tools undermine their professional skills and judgment (Andrews and Bonta, 1998; Aubrey and Hough, 1997). Information necessary to complete risk assessments is collected via multiple sources; typically the responding police officer, victim advocates from the local police department or court (or both), jail intake officers, and existing criminal history record databases. 
A growing body of research focusing on risk factors for repeat victimization has spurred the implementation of risk-focused information collection by police in response to incidents of IPV/DV in the United States and United Kingdom (Campbell et al., 2009; Robinson, 2006). Research has demonstrated that a large and expanding proportion of U.S. police agencies employ some form of IPV/DV risk assessment instrument (Messing et al., 2015; Police Executive Research Forum, 2015) while police in the U.K. have utilized the Domestic Abuse, Stalking, and Honor Based Violence risk assessment tool since 2009 (Robinson et al., 2016). Despite wide recognition that police should, and have been, adopting risk-led approaches to IPV/DV, the utility of this approach continues to be hindered by practical shortcomings (Bland and Ariel 2015; Hoyle, 2007). Specifically, police lack an awareness and understanding of how risk assessments can inform effective IPV/DV responses and that ambiguity exists among police as to how information they collect for IPV/DV risk assessments is utilized subsequently by other actors in the criminal justice system in the United States (Campbell et al., 2009), United Kingdom (Her Majesty’s Inspectorate of the Constabulary, 2014; Robinson et al., 2016), Canada (Blaney, 2010), and New Zealand (Grant and Rowe, 2011).

Research has found police tend to focus their information collection efforts on evidentiary value as opposed to the validation of risk assessments (Grant and Rowe, 2011). Moreover, police may be unaware of how risk factors they perceived to be non-significant may be vital for other system partners when making determinations about IPV/DV risk (Stanley and Humphreys, 2014). Trujillo and Ross (2008) concluded that police use only a few heuristic indicators to assess risk and make decisions. As a result, when asking officers to record new risk assessment information that deviates from commonly held shorthand metrics, the collection should be consistent to the information that is used to make arrest decisions.

The role of the police as information collectors and assessors of risk at the response stage of IPV/DV incidents was echoed by Hester and Westmarland (2005) in their challenge to scholars to research how police information is collected and assessed during the initial interviewing process for 
IPV/DV offenses. Moreover, the benefits of information collection by police at the scene of IPV/DV incidents can extend beyond the completion of risk assessments to further enhance case processing and criminal justice system outcomes of IPV/DV arrestees. Incomplete police reports or those lacking sufficient detail, have been found to significantly increase the likelihood that prosecutors decide to drop IPV/DV charges (Dawson and Dinovitzner, 2001; Ferraro and Boychuk 1992; Horwitz et al., 2011). While the integration of new information collections at the scene or additional documentation in existing reports will undoubtedly be perceived as having to do more work (Carter and Grommon, 2016), the role of the police as integrators of risk assessment tools has the potential to further enhance criminal justice system processes. Systematic on-scene collection of critical information and assessment of risk can translate to subsequent efficiencies in prosecution and sentencing decisions, particularly system determinations at pretrial for IPV/DV incidents.

Police Interactions with Victims of Intimate Partner and Domestic Violence

The aforementioned collection of information by police in response to IPV/DV incidents is directly contingent on the willingness of the victim to cooperate with police. Cooperation with the police is inhibited by a number of factors. Research suggests victims may remain intimidated by the arrestee or fear reprisal if they cooperate with the police or broader criminal justice system (Dawson and Dinovitzner, 2001; Erez and Belknap, 1998; Ford, 1983; Singer, 1988). Using interviews with 49 female victims of IPV/DV, Bennett et al. (1999) concluded that uncooperative victims remained fearful of continued victimization during pretrial, expressed confusion about court processes, and were frustrated by the criminal justice system as a whole. Evidence from victims of IPV/DV has demonstrated that responding officers who provide resources and assistance are perceived to be the most helpful (Apsler et al., 2003; Johnson, 2007). Responding officers who cast a respectful and carrying demeanor are most likely to gain victim cooperation and increase the likelihood victims report future IPV/DV offenses (Stephens and Sinden, 2000). This body of research indicates police behavior 
and practice when responding to incidents of IPV/DV are influential in delivering quality service, shaping victims' cooperation with, and perceptions of, the criminal justice system, and improving IPV/DV case outcomes.

\section{Police as Interagency Partners}

Efforts to pair police with community correctional agencies continue to grow in popularity in the United States (Murphy, 2008) and are representative of a movement toward maintaining surveillance on high risk populations in the criminal justice system as a whole (Cotter and De Lint, 2009; Ibarra et al., 2014; Jannetta and Lachman, 2011; McGarrell et al., 2005; Paterson and Clamp, 2014). These partnerships have the potential to enhance public safety by adding focused deterrence and an additional layer of monitoring to known offenders under supervision, interrupting criminal behaviors through timely responses, and addressing locally specified crime problems through intelligence sharing (Jannetta and Lachman, 2011: McGarrell et al., 2005; Murphy, 2008). To accomplish these objectives, interagency collaborations and victim-focused approaches must be viewed as a core police function, rather than simply being a series of buzzwords (Murphy, 2008; Paterson and Clamp, 2014; Worrall and Gaines, 2006).

GPS technology has been employed as a tool to fulfill surveillance goals for criminal justice agencies. GPS technology is able to track offender movements in near real time and is assumed to reduce crime and repeat victimization by altering the routine activities of offenders and increasing the likelihood that police, community correctional agencies, or both will be able to detect criminal behavior or associated non-compliance with supervision terms. In order to maximize the potential benefits of this form of technology, the police must assist with daily monitoring and response activities (DeMichele and Payne, 2009; Gowen, 2001). 
Yet, the roles or practices police can or should assume - as a responder to IPV/DV incidents; an information collector; a risk assessor or integrator of risk assessment tools; an interagency partner - is unclear and is further confounded by the growing implementation of GPS supervision programs in the United States. The present study lends additional evidence to examine and extend the body of research on police roles and responses to preventing or reducing repeat IPV/DV victimizations. The generalized research question concerns the roles or practices police should take on after an IPV/DV arrest has been made and an arrestee (now defendant in front of the court) has been placed on GPS supervision. The focus of the research reported here is the perception of police roles and responses among victims, victim advocates, and those tasked with the responsibility of directly supervising alleged assailants during pretrial. This research gives victims an active voice, which is quite uncommon from extant knowledge of IPV/DV incidents (Cotter and De Lint, 2009). Furthermore, this research fundamentally acknowledges that police roles and responses do not end once an incident has been processed. Instead, police roles continue to be shaped by subsequent responses after an arrest and in collaboration with other criminal justice system actors.

\section{Methods}

The present study reports findings gleaned from a broader case study project funded by the National Institute of Justice to examine the GPS supervision of pretrial IPV/DV defendants. ${ }^{2}$ The location of the original research study was a large city-county jurisdiction of approximately three million people in the western region of the United States. The location was chosen through a selection

\footnotetext{
${ }^{2}$ This work was supported in part by the U.S. Department of Justice, Office of Justice Programs, National Institute of Justice (award 2010-IJ-CX-K023). The opinions, findings, conclusions, and recommendations expressed in this manuscript are those of the authors and do not necessarily reflect those of the U.S. Department of Justice, Office of Justice Programs, National Institute of Justice. The authors have no vested interests in commercial communication technology products, processes, or services.
} 
process wherein an eligible jurisdiction had to demonstrate a sizeable IPV/DV population managed by GPS technology in addition to having a rather mature experience with GPS technology to better inform best practice discussions for other localities looking to implement a new program or modify their existing practices.

The study site is located in a state that requires police to determine the primary aggressor in an IPV/DV incident and place that person under arrest. From 2009-2014, the jurisdiction averaged 658 misdemeanor IPV/DV cases and 270 felony cases per year. In 2014 there were approximately 400 IPV/DV defendants assigned to pretrial GPS supervision. The average defendant ordered to pretrial GPS supervision was a 35 year old white, non-Hispanic male who is being charged with two municipal or misdemeanor offenses with the most serious offense charge including an assault. Twenty percent of the defendants ordered to GPS supervision were charged with a felony offense. In terms of past criminal histories, 67 percent of the defendants had received a previous jail sentence, 32 percent had served a prior prison sentence, and 26 percent were under community correctional supervision at arrest. Fifty-six percent of the defendants had been arrested for a previous domestic violence offense. Defendants were released on a median bond of $\$ 2,000.00$ (USD) and were supervised for an average of 128 days.

The jurisdiction employs a one-piece GPS ankle bracelet and subscribes to a monitoring plan where the device collects GPS data from satellites every minute when a defendant is not in violation and every 15 seconds when a defendant is in violation. Active GPS tracking is used where collected GPS data are reported to a centralized monitoring center and the supervising pretrial probation officer via cellular communications and a secure website. Pretrial probation officers are notified of a variety of alert events on departmental issued cell phones and email accounts. Pretrial probation officers can "ping” a device at any time to determine location and can communicate 
directly to a defendant using pre-recorded messages that must be acknowledged and cleared on the device.

\section{Context of GPS Assignment and Exclusion Zones in the City of Study}

Policy and practice are as important to system operations as the actors involved (Erez et al., 2012), therefore some detail on policies and practices of the study site are necessary. The site employs two risk assessment tools to guide pretrial GPS assignment. One risk assessment is designed to assess the likelihood for pretrial misconduct (i.e., failure to appear to court, commission of a new offense, or both). The second is specific to IPV/DV offenses and attempts to gauge the likelihood a defendant will recidivate against the victim. Scores from these two risk assessments are used in tandem with an established matrix tool vetted by local presiding judges, prosecutors, and defense counsel representatives to recommend placement of defendants into one of four overall risk categories, each of which corresponds to a level of supervision. GPS supervision is recommended for higher risk defendants who require frequent in-person case management meetings prior to and after court hearings. This is the most intense level of pretrial supervision available in the jurisdiction. Supervision recommendations are presented by pretrial staff to the presiding judge at first advisement when bond orders are set and defendants have been provided with their charges and informed of their right to counsel. The decision to place defendants on GPS supervision is ultimately at the discretion of the judge. If pretrial release is granted and conditional GPS supervision conditions are ordered, pretrial GPS supervision is mandated. The average defendant ordered to GPS supervision in 2014 had a low-moderate risk score for pretrial misconduct and a moderate-high risk score for future assault against a partner. Nearly 80 percent of defendants who are recommended to placement on GPS supervision are ordered to this form of supervision. 
Pretrial probation officers are tasked with the responsibility of monitoring supervision terms ordered by the court, which at minimum will correspond to mandatory protection orders requiring defendants to stay away from a victim at all times and refrain from contacting or communicating with victim(s). Supervision terms require defendants to pay supervision fees. In some instances, defendants may also be ordered to urine testing, curfews, or both. Defendants who violate supervision terms may have their pretrial supervision status revoked, have new supervision conditions ordered, have new charges filed, or have warrants issued.

The study site utilizes exclusion zones with a configuration of outer and inner zones. An outer exclusion zone is typically a 1,000 foot radius surrounding a victim's known or routine location, such as home, work, or children's school. An inner exclusion zone is the inner-most, or center, area within the outer zone. Inner zones are typically a 300 foot radius and correspond directly to the specified terms of a mandatory protection order requiring defendants to stay 100 yards away from a victim. The study site uses both zones in an effort to enhance responses to non-compliant behavior. In the event of an outer zone violation, pretrial probation officers are required to diagnose the violation and take appropriate action. In some instances a defendant may have accidentally entered the outer zone, such as traveling on a major roadway. In other instances, a defendant may have entered the zone and either remains in the perimeter areas of the outer zone or continues to proceed to the center of the zone. From a policy perspective, the inner zone triggers pretrial probation officer mediated notifications to victims, supervising pretrial probation officers, and the police. Defendants who enter inner exclusion zones are pressing public safety concerns that require immediate action from pretrial services and the police. The police therefore play an important role in responding to supervision violations and alerts emanating from GPS technology systems.

[INSERT FIGURE 1 ABOUT HERE] 
Figure 1 provides a simple illustration of the communication pathways that are followed once a GPS alert is triggered. At the outset, it is important to note that GPS supervision relies on the decisionmaking of human actors who must actively interpret and respond to an alert and do so with bounded discretion according to local policy and practice (see Salvemini et al., 2015). Solid arrows correspond to communication pathways that occur for a response to any type of GPS alert. That is, once a GPS alert is triggered the notification goes directly to a centralized monitoring center and a supervising pretrial probation officer. A feedback loop is built into the communication between the monitoring center and the officer to exchange information. Pretrial probation officers use proprietary GPS tracking software to gather information, which generally consists of summary data pushed by the monitoring center to pretrial probation officers. The pretrial probation officer interprets and processes the alert and then corresponds with a defendant through the GPS device or by other means of direct communication. The defendant can then acknowledge a message from a supervising pretrial probation officer and clear an alert.

Dotted or dashed arrows depicted in Figure 1 correspond to discretionary communication pathways. Not all alerts require communication to victim advocates, victims, or the police. Exclusion zone violations are the exception, as are low battery, lost signal, or tampering alerts that result in the defendant being unmonitored. These type of alerts place victims most at risk for repeat victimization. In these instances, communication and information exchange flows across all of the pathways. Police play an active role in responding to these alerts and are expected to provide reciprocal communication exchanges.

To provide perspective on the anticipated workload burden on pretrial probation officers and police, most of the defendants (69\%) had at least one high priority GPS alert that placed the defendant in violation of supervision terms. Defendants generated an average of four high priority alerts across their pretrial supervision term. Most of the alerts that triggered a violation resulted 
from an entry into an exclusion zone. As mentioned, this type of alert requires an immediate response as a matter of policy and practice and is most likely to require the dispatch of local police. Other alerts include low battery, out of range or lost signal, and device or device strap tampering in descending order.

\section{Data Collection}

While quantitative examinations provide important descriptive information on agency operations, they lack the ability to properly contextualize nuances of complex processes; a strength of qualitative research. In-depth interviews serve as the qualitative component of the present study. This is the preferred approach as the technique allows researchers to capture insights on how agency operations are perceived (Rubin and Rubin, 1995). This is especially true with respect to many facets of the criminal justice system broadly (Bales et al., 2010; Greene, 2014) and IPV/DV incidents more specifically (Ibarra and Erez, 2005). Qualitative data was generated from a series of face-to-face and telephone interviews with justice personnel (i.e., pretrial program administrators, probation officers, victim advocates from two prosecution offices, and intake personnel) as well as IPV/DV victims. Data is presented in the form of themes developed through systematic analyses of interview responses.

Two site visits were conducted. The first to learn about the criminal justice system of the study site and the second to conduct interviews. In-depth interviews were conducted using a semi-structured interview instrument. This instrument included both specific questions with Likert scale response categories and open-ended items to allow respondents to convey their perceptions while also enabling unstructured follow-up questions. Two separate interview instruments were developed to target perceptions of justice personnel and victims. Items included on each instrument were gleaned from a combination of previous research (Bales et al., 2010; Erez et al., 2012; Irbarra and Erez, 2007), 
discussions with justice personnel from the study site, and GPS technology hardware and software experts.

Pretrial probation officers at the study site are assigned to either a technology caseload that includes defendants placed on some form of electronic monitoring (i.e., GPS, radio frequency, or alcohol monitoring) or a non-technology caseload that only include defendants who are supervised without the use of technology. Interviews were conducted with all seven of the pretrial probation officers responsible for managing technology caseloads. Three victim advocates were interviewed; one from the prosecutor's office who assists felony and misdemeanor cases and two from the prosecutor's office who manages municipal cases. The final justice personnel interviewed for the study was a pretrial intake officer assigned to gather defendant information prior to an initial bond hearing. Interviews with justice personnel averaged 55 minutes. All of the probation officers interviewed for the study were female, had been employed in their current position for an average of six years, and were responsible for an average case load of 95 defendants. Victim advocates interviewed were all female as well and had worked in this position for an average of five years.

Three victims whose defendant was ordered to pretrial GPS supervision agreed to be interviewed for this study. Victims (all women) were recruited for the study by one victim advocate who worked for the prosecution office responsible for municipal cases. Victims were provided copies of the research consent form at the time they were contacted about their interest in participating in this study. Individual interviews were conducted with victims via telephone to minimize the burden of participation and further anonymize their identity. Interviews averaged 30 minutes.

Interviews with all persons for this study were audio recorded. In addition, detailed notes were taken individually by the authors. These sources of information were transcribed into a single source document. To enhance the validity of interpretations from the interviews (King, 1994), additional teleconferences and continual communication with justice personnel occurred to solicit feedback, clarify, and reaffirm the information gathered. 


\section{Discussion of Findings}

Three main findings pertaining to police roles and practices in the pretrial GPS supervision of IPV/DV defendants are presented. Each finding is identified below with underlined text followed by a discussion of how each finding was manifested and contextualized. Only those themes that gained consensus and saturation among those interviewed are reported. Given the inherent issues of maintaining the confidentiality of a small sample who discuss potentially sensitive information and pragmatic space considerations, qualitative data (in the form of direct quotes) are not presented. Limitations to these findings are reported in the subsequent section.

IPV/DV risk assessment tools can be enhanced through police information collection at the time of incident response.

The IPV/DV risk assessment tools used at the study site relies upon victim advocates to successfully contact the victim and extract answers to score items. The timeline to contact the victim is narrow as risk assessment scores need to be generated prior to the defendant's appearance for a bond hearing the morning following the incident. Victim advocates are not always able to successfully obtain information from the victim due to an assortment of factors. For instance, victims may have had their cell phone destroyed by the defendant. A victim may also be unwilling to cooperate. As a result, risk assessment tools cannot be used to their full potential and the decision to place defendants to forms of pretrial supervision may be misinformed (e.g., low risk defendants are ordered to GPS supervision while high risk defendants are not ordered to GPS supervision).

Further complicating this process is the fact that the responding police officer may not capture the necessary information to score a risk assessment instrument. At the time of the study, the jurisdiction was working with the police to develop an IPV/DV incident report where the responding officer asks and documents standardized questions that allow other justice personnel to access the 
report and use the information to accurately complete assessment instruments. Not only would this reporting procedure assist with the collection of necessary information, but it would also make this information accessible in the timely window needed to inform pretrial bond and supervision decisions.

Taking the role of an information generator or integrator of assessment tools does come at a cost above and beyond common reporting demands. Momentum towards an automated police field report with risk assessment items in the study site is anticipated to replace an existing illustrative report that allowed for the documentation of bodily injury to the victim and the defendant. This report was useful in helping to determine the lethality of the incident; an aspect justice personnel noted as being a weakness of risk assessment tools. Victim advocates were working with the police to develop a reporting mechanisms to capture all desired risk assessment information in addition to the illustrative injury information at the time of data collection. The need to communicate the importance of collecting such information is salient to counter potential police role ambiguity as this information may run against the grain of what information police traditionally report.

IPV/DV charges can be brought in district court as a felony or misdemeanor or in a circuit court as a municipal offense at the study site. The prosecution decision is made from a review of the police report. Victim advocates interviewed in both prosecution offices indicated a heavy reliance on reports in informing charging decisions. Victim advocates expressed common occurrences when charges initially filed as misdemeanors were subsequently refiled as felony cases following further correspondence with victims. These refiles were perceived to be the result of information that was not included in the police report. There was a commonly held belief among both victim advocates and pretrial probation officers interviewed that improved police reporting, in the form of quality and additional information collected, would facilitate a more effective criminal justice response to IPV/DV offenses. This finding is consistent with previous research that suggests police reports of IPV/DV incidents can influence case outcomes (Dawson and Dinovitzner, 2001; Ferraro and Boychuk 1992; Horwitz et al., 2011). 
Police response to GPS violations and alerts can improve IPV/DV victims' perceptions of the criminal justice system.

Previous research suggests victims of IPV/DV express frustration with the criminal justice system and continued fear of victimization following the defendant's arrest and case disposition (Bennett et al., 1999; Dawson and Dinovitzner, 2001; Erez and Belknap, 1998; Singer, 1988). Police are called to conduct welfare checks of victims in the event a defendant enters the inner exclusion zone or fails to exit the outer zone at the study site. Victim advocates and victims interviewed for the present study communicated a welcomed sense of safety and attentiveness on behalf of the criminal justice system when describing police responses to GPS exclusion zone violations. Victims, as well as victim advocates speaking generally about the victims they served, believed that police responses signaled attentiveness on behalf of the criminal justice system. Cases were perceived by victims to be taken seriously. Moreover, desired resources affiliated with police protection were viewed as being delivered.

A challenge for the police in fulfilling the role of being a responder to supervision violations or alerts is the potential for service call burnout that in turn affects justice personnel and victim perceptions of the police and vice versa. Exclusion zone violations are high priority alerts for justice personnel and victims and become ever more critical to respond to when a defendant enters an inner exclusion zone. Pretrial probation officers discussed at length the emotional toll these alerts create as they monitor defendant movement and await police contact. Themes of frustration were presented as pretrial probation officers elaborated upon incidents where there may be delays in police response. These frustrations stemmed from perceived mismatches between priority rankings of pretrial probation officers and police officers. Such challenges are common among police-community corrections partnerships (Jannetta and Lachman, 2011; McGarrell et al., 2005; Murphy, 2008). While probation officers interpreted these events as top priority, probation officers perceived police to view these events 
as low priority calls attended to after other priorities have been cleared. At the same time, pretrial probation officers recognized that continued calls to conduct welfare checks can be burdensome on the police. This was especially true in those instances where defendants have exited exclusion zones in the interim between a detected alert and police arrival.

Exclusion zone violations are not the sole alert that lead to a police service call. Defendants may also fail to comply with supervision requirements of maintaining their GPS unit. Most common at the study site were failures to charge the GPS unit battery. Attempts to remove, modify, or tamper with the GPS unit also generate alerts (albeit to a much less frequent extent). Both of these events can lead to defendants becoming unmonitored for various lengths of time. Jurisdiction policy dictates that victims be notified in the event a defendant becomes unmonitored. Victims interviewed had experienced at least one of these events in the past. All of the victims discussed increased levels of anxiety and fear upon learning of an unmonitored status. Victim advocates expressed receiving positive and cooperative reactions from police when asked to assist victims in these situations. Victim advocates expressed that police accommodated requests for deploying additional patrols in the victim's residential locations. It was explained that in some cases police personnel have gone to lengths that include sitting in their vehicle directly in front of the victim's home for further safety.

Pretrial probation officers and victim advocates emphasized the need to communicate realistic expectations of police responses to GPS violations and alerts. Advocates summarized expectations of victims who believe the police will immediately respond and apprehend a defendant given GPS technology captures defendant locations. Victims interviewed perceived pretrial probation officers, as well as police, to be monitoring every defendant at real-time whereby someone is watching a screen and constantly monitoring defendant movement. Victim advocates shared their experiences with victims that became upset when police did not immediately apprehend a defendant who violated court orders under GPS supervision as victims were under the impression this was the expected police response. Victims questioned the purpose and legitimacy of the police in these instances. Pretrial 
probation officers and victim advocates worked to provide clear descriptions of what the technology can and cannot do to temper these perceptions of the police.

Effective communication and information sharing is critical as the police are among the primary points of contact for justice personnel and victims as cases move forward in the criminal justice system.

Discussions with victim advocates and victims alluded to the police being the first information source who can detail what will happen to the arrestee and how the system will keep the arrestee from doing further harm to the victim. When arrestees are placed on pretrial GPS supervision the police are again perceived by victims as being able to describe what will happen and what the police will do to prevent future contacts. Victims described receiving an array of information on available social services and resources from the police and victim advocates. Comments from victim advocates indicated that police are generally helpful in either of these two circumstances, although the desire for more information was requested regardless of the content of the shared material. Victim advocates believed it would beneficial for the police to provide victims with specific information, in the form of a printed pamphlet, that explained the criminal justice process generally and GPS program more specifically. Victim advocates explained that victims, even if provided accurate information verbally, are unlikely to fully comprehend the information exchanged during a police response. Victims appreciated follow-up communication when it was provided from the police, victim advocates, or both.

The lack of communication or information sharing was also perceived to cause problems for victims. Pretrial probation officers and victim advocates discussed the unintended consequences that occur when a defendant under GPS supervision is arrested. Upon arrest GPS devices are removed from the defendant as filing decisions and jail bookings are made. Pretrial probation officers receive alerts for unit tampering and are unable to reach the defendant. Victims are notified that defendants are unmonitored. Pretrial probation officers and victim advocates indicated that police do not always contact justice personnel to inform of the arrest and removal of the GPS unit. This break in 
communication was perceived to leave victims in the dark regarding the defendant's supervision status. The affiliated anxiety and fear victims may experience was viewed as being unnecessary as defendants were incapacitated.

There was consensus among justice personnel interviewed that police should be required to report arrests to pretrial probation officers as quickly as possible. This communication would allow the defendant's pretrial probation officer to be aware of the arrest and take appropriate actions. Perhaps more importantly, this would also inform the pretrial probation officer of the circumstances surrounding the GPS alert. Pretrial probation officers indicated they would contact the victim to notify them of the arrest, but that this notification would carry a significantly different message to victims than would a notification that the defendant was simply not being monitored.

\section{Conclusion and Discussion}

The present study reports findings that illustrate that police roles and responses to IPV/DV offenses are evolving and continue to move away from traditional crime control and surveillance functions toward enhancing the capacity of the criminal justice system to function effectively. In the context of the emerging system practice of placing IPV/DV arrestees under pretrial GPS supervision, police may serve a number of roles. Information generators, information assessors, information sharers, integrators of assessment tools, interagency partners, and alert responders were the principle roles observed in this case study. These roles, whether actively undertaken by the police or passively attributed to the police by others, will influence expectations and how responses are perceived by actors in the criminal justice system, victims, and the public as a whole. In turn, these perceptions will shape impressions of police legitimacy and the ability of the police and the broader justice system to reduce or prevent IPV/DV crimes.

In addition to managing the multiple complex roles and expectations reported, police practitioners may wish to consider lessons learned from the current case study to inform discussions 
of policy and practice. Police should embrace the current movement towards data-driven practice that rely on patrol officers to be collectors and disseminators of information to inform all aspects of police operations, service, and strategic planning (Carter, 2015). Though such data-driven efforts face resource and cultural challenges within policing (Chan, 2001; Carter and Grommon, 2014; Ioimo and Aronson, 2004), they position police to enhance law enforcement practice specifically and criminal justice system operations that rely upon interagency partnerships more generally.

Research has shown that as few as 41 percent of police agencies have procedures for police to interact with victims in response to IPV/DV (Townsend et al., 2006). Police should collaborate with other criminal justice system stakeholders to develop IPV/DV field reporting procedures. Such procedures should incorporate the collection of information to score risk instruments, gather evidence for prosecution, and also deliver desired informational resources to victims. Existing research and the findings from the present study illustrate that such efforts can improve IPV/DV case processing as well as improve perceptions of police and criminal justice system legitimacy among victims. In jurisdictions that utilize GPS, or seek to implement such a program, informational resources to provide victims of IPV/DV may include pretrial probation office contact information as well as police and pretrial policy on responding to GPS calls for service that may temper expectations of victims regarding police response.

Lastly, jurisdictions that utilize GPS supervision of IPV/DV defendants should consider the creation of information liaison officers to enhance communication between police, jails, and pretrial probation officers. Liaison officers serve as a single point of contact to facilitate timely and accurate inter-organizational information exchange. The present study highlighted the collateral issues that result from GPS units being removed from defendants upon a new arrest as well as lagged or inconsistent information sharing during police response to IPV/DV calls for service. Liaison officers could improve information flow that may alleviate undo anxiety and fear among victims in cases where GPS defendants become unmonitored for a variety of reasons. 


\section{Study Limitations}

This study is not without limitations. The case study design enables the ability to observe experiences and activities that have occurred in one jurisdiction and how such events are perceived. The unfortunate trade-off with these designs is generalizability; it is not clear if the thematic trends and data gathered from the study site would be applicable for other jurisdictions. Given that the study site was selected due to its mature experience using pretrial GPS supervision for IPV/DV defendants and has been involved in training administrators on implementation of their program model, some of the generalizability concerns may be reduced but are not completely resolved.

Along these same lines, three victims agreed to participate in the study. Victim perceptions while insightful and interesting - cannot be considered representative to the larger population of IPV/DV victims within or external to the study site. No attempts were made by the researchers to access, identify, or otherwise contact victims to participate in this study. Instead, one victim advocate facilitated these interviews. This process is common in IPV/DV research and has been referred to as reactive sampling (Ibarra and Erez, 2005). To avoid an overreliance on victim interviews, only those instances where pretrial probation officers, victim advocate, and victims discussed overlapping themes (i.e., achieve qualitative saturation) are presented as findings.

Besides two representatives from the local police department's victim advocate unit who provided an introductory overview of their operations during the first site visit, no police personnel were interviewed for this study. While a number of the insights gained from the initial visit were also mentioned by victim advocates from prosecution offices who participated the data collection that took place during the second site visit, the assertions, practices, or policy discussions could not be verified with the local police department. Based on discussions with personnel interviewed, the gap between police and pretrial probation officers appears to be the result of miscommunication, unclear boundaries and responsibilities, and a lack of awareness among the police with respect to the impact their practices 
can have on effective GPS supervision. These are known challenges with interagency partnering and should be anticipated among agencies seeking to develop new partnerships or amend existing relationships (Jannetta and Lachman, 2011; McGarrell et al., 2005; Murphy, 2008). During the study period it was made apparent that both pretrial and victim advocate personnel were in the process of improving communication channels between the police and other system partners to improve police responses to IPV/DV. The decision to focus on interviews with pretrial justice personnel was made to best capture perceptions and practices from staff who are closely tied to the necessary tasks of managing the supervision of IPV/DV defendants. Moreover, these interview participants provided unique insights on police collaborations and where such efforts could be improved. While research has been conducted on victims' attitudes or perceptions toward the police (Stephens and Sinden, 2000), there has been little to no research on the views of victim advocates or pretrial probation officers about the police. This study provides first steps to understanding these unique relationships and criminal justice responses to IPV/DV offenses.

\section{Directions for Future Research}

A review of the literature examining police response to IPV/DV incidents revealed a lack of attention to the role of the police as information providers who influence criminal justice system processing such as bond and pretrial supervision decisions. The present study identified unique insights to help inform this shortcoming as well as avenues for future social inquiry. To begin, there needs to be a systematic collection of data pertaining to organizational police procedures in response to IPV/DV incidents. For example, the 2013 Law Enforcement Management and Administrative Statistics (LEMAS) survey conducted by the U.S. Bureau of Justice Statistics only includes one metric pertaining to police agencies and IPV/DV; whether or not the department has a specialized domestic violence unit. This metric provides little insight into what activities police are required to conduct when 
responding to IPV/DV incidents. Additional metrics that capture such practices should be considered for inclusion in LEMAS and other organizational-level assessments of police practice and policy.

Scholars should examine the extended roles of the police during and after IPV/DV encounters. Methods such as systematic social observation, in-depth case studies from multiple jurisdictions, and quasi-experimental designs should be employed to assess the impact of police service delivery on victims of IPV/DV, victim advocates, and pretrial probation officers. Outcome metrics should extend beyond prosecutorial decisions, victim cooperation, and recidivism to include perceptions of various criminal justice system stakeholders and victims that pertain to police and criminal justice system legitimacy. Moreover, the review of literature exposed a general lack of scholarly attention paid to the role of police in GPS supervision. Scholars examining community supervision, especially GPS monitoring, should broaden their focus to include police policies and practices and how such actions can impact the operations of other criminal justice system partners. Lastly, scholars should examine police perceptions of their role as responders to IPV/DV incidents. It is unclear whether or not police are aware of their role in the broader criminal justice system response to IPV/DV and how their actions (or inactions) may impact case processing, legitimacy, and effective intervention. 


\section{References}

Andrews, D. A., and Bonta, J. (1998). The Psychology of Criminal Conduct (2nd Ed.). Cincinnati, $\mathrm{OH}$ : Anderson.

Apsler, R., Cummins, M. R., and Carl, S. (2003). Perceptions of the police by female victims of domestic partner violence. Violence Against Women, 9(11): 1318-1335.

Aubrey, R., and Hough, M. (1997). Assessing Offenders' Needs: Assessment Scales for the Probation Service. Home Office Research Study. No. 166. London: Home Office, Research, Development and Statistics Directorate.

Bales, W., Mann, K., Blomberg, T., Gaes, G., Barrick, K., Dhungana, K. and McManus, B. (2010). A Quantitative and Qualitative Assessment of Electronic Monitoring. U.S. Department of Justice. NCJ 230530.

Bennett, L., Goodman, L. and Dutton, M. A. (1999). Systemic obstacles to the criminal prosecution of a battering partner: A victim perspective. Journal of Interpersonal Violence, 14(7):761772.

Bland, M., and Ariel, B. (2015). Targeting escalation in reported domestic abuse: Evidence from 36,000 callouts. International Criminal Justice Review, 25(1), 30-53.

Blaney, E., (2010). Police officers' views of specialized intimate partner violence training. Policing: an International Journal of Police Strategies and Management, 33(2), 354-375.

Block, C. R. (2003). How can practitioners help an abused women [sic] lower her risk of death? NIJ Journal, 250. NCJ 196545.

Campbell, J. (1995). Prediction of Homicide of and by Battered Women. In J. Campbell (Ed.), Assessing the Risk of Dangerousness: Potential for Further Violence of Sexual Offenders, Batterers, and Child Abusers, 93-113. Thousand Oaks, CA: Sage.

Campbell, J. (2004). Helping women understand their risk in situations of intimate partner violence. Journal of Interpersonal Violence, 19(12): 1464-1477.

Campbell, J. C., Webster, D. W., and Glass, N. (2009). The danger assessment: validation of a lethality risk assessment instrument for intimate partner femicide. Journal of interpersonal violence, 24(4), 653-674.

Campbell, J., Webster, D., Koziol-McLain, J., Block, C., Campbell, D., Curry, M., et al. (2003). Risk factors for femicide in abusive relationships: Results from a multi-site case control study. American Journal of Public Health, 93(7): 1089-1097. 
Carter, J. G. (2015). Inter-organizational relationships and law enforcement information sharing post-September 11, 2001. Journal of Crime and Justice, 38(4): 522-542.

Carter, J. G. and Grommon, E. (2016). Officer perceptions of the impact of mobile broadband technology on police operations. Policing and Society. Advanced Online Publication. DOI: 10.1080/10439463.2015.1112388.

Carter, J. G. and Grommon, E. (2014). Wireless broadband for municipal police: Evaluating clearance times of calls for service. Police Quarterly, 17(3): 226-249.

Chan, J. B. L. (2001). The technological game: How information technology is transforming police practice. Criminology and Criminal Justice, 1(2): 139-159.

Clarke, R. V. and Eck, J. E. (2005). Crime Analysis for Problem Solvers in 60 Small Steps. Washington, D.C.: U.S. Department of Justice, Office of Community Orientated Policing Services.

Cotter, R. and De Lint, W. (2009). GPS-electronic monitoring and contemporary penology: A case study of US GPS-electronic monitoring programmes. The Howard Journal of Criminal Justice, 48(1), 76-87.

Dawson, M. and Dinovitzer, R. (2001). Victim cooperation and the prosecution of domestic violence in a specialized court. Justice Quarterly, 18(3): 593-622.

DeMichele, M. and Payne, B. (2009). Offender Supervision with Electronic Technology: Community Corrections Resource ( $2^{\text {nd }}$ Ed.). Washington, D.C.: U.S. Department of Justice, Office of Justice Programs, Bureau of Justice Assistance.

Durose, M. R., Harlow, C. W., Langan, P. A., Motivans, M., Rantala, R. R., and Smith, E. L. (2005). Family Violence Statistics Including Statistics on Strangers and Acquaintances. Bureau of Justice Statistics. Washington DC: U.S. Department of Justice. NCJ 207846.

Dutton, D. G., and Kropp, P. R. (2000). A review of domestic violence risk instruments. Trauma, Violence and Abuse, 1(2): 171-181.

Erez, E., and Belknap, J. (1998). In their own words: Battered women's assessment of the criminal processing system's responses. Violence and Victims, 13(3): 251-268.

Erez, E. and Ibarra, P. (2007). Electronic monitoring and victim re-entry in domestic violence cases. British Journal of Criminology, 4: 100-120. 
Erez, E., Ibarra, P.R., Bales, W.D. and Gur, O.M. (2012). GPS Monitoring Technologies and Domestic Violence: An Evaluation Study. Washington, D.C.: U.S. Department of Justice, National Institute of Justice. NCJ 238910.

Fagan, J. (1996). The Criminalization of Domestic Violence: Promises and Limits. National Institute of Justice, Washington, DC.

Finn, M., Blackwell, B., Stalans, L., Studdard, S. and Dugan, L. (2004). Dual arrest decisions in domestic violence cases: the influence of department policies. Crime and Delinquency, 50(4): 565-589.

Ford, D. A. (1983). Wife battery and criminal justice: A study of victim decision-making. Family Relations, 32(4): 463-475.

Frye, V., Haviland, M., and Rajah, V. (2007). Dual arrest and other unintended consequences of mandatory arrest in New York City: a brief report. Journal of Family Violence, 22(6): 397405.

Gowen, D. (2001). Remote location monitoring - A supervision strategy to enhance risk control. Federal Probation, 65(2), 38-41.

Grant, S. and Rowe, M. (2011). Running the risk: Police officer discretion and family violence in New Zealand. Policing and Society, 21(1): 49-66.

Greenfeld, L. A., Rand, M. R., Craven, D., Klaus, P. A., Perkins, C. A., Ringel, C., Warchol, G., Maston, C., and Fox, J. A. (1998). Violence by Intimates: Analysis of Data on Crimes by Current or Former Spouses, Boyfriends, and Girlfriends. Bureau of Justice Statistics. Washington DC: U.S. Department of Justice. NCJ \#167237.

Her Majesty’s Inspectorate of the Constabulary. (2014). Everyone's Business: Improving the Police Response to Domestic Violence. London. Retrieved from https://www.justiceinspectorates.gov.uk/hmic/wp-content/uploads/2014/04/improvingthe-police-response-to-domestic-abuse.pdf

Hester, M. and Westmarland, N. (2005). Tackling Domestic Violence: Effective Interventions and Approaches. Home Office Research, Development and Statistics Directorate. London, United Kingdom.

Hirschel, D., Buzawa, E., Pattavina, A. and Faggiani, D. (2007). Domestic violence and mandatory arrest laws: to what extent do they influence police arrest decisions? Journal of Criminal Law and Criminology, 98(1): 255-298. 
Horwitz, S. H., Mitchell, D., LaRussa-Trott, M., Santiago, L., Pearson, J., Skiff, D. M., and Cerulli, C. (2011). An inside view of police officers’ experience with domestic violence. Journal of Family Violence, 26(6): 617-625.

Houry, D., Feldhaus, K., Peery, B., Abbott, J., Lowenstein, S. R., Al-Bataa-de-Montero, S., et al. (2004). A positive domestic violence screen predicts future domestic violence. Journal of Interpersonal Violence, 19(9): 955-966.

Hoyle, C. (2007). Will she be safe? A critical analysis of risk assessment in domestic violence cases. Children and Youth Services Review, 30(3), 323-337.

Ibarra, P. R., Gur, O. M., and Erez, E. (2014). Surveillance as casework: Supervising domestic violence defendants with GPS technology. Crime, Law, and Social Change, 62(4), 417444.

Ibarra, P. R. (2005). Red flags and trigger control: The role of human supervision in an electronic monitoring program. Sociology of Crime, Law, and Deviance, 6: 31-48.

Ibarra, P. R. and Erez, E. (2005). Victim-centric diversion? The electronic monitoring of domestic violence cases. Behavioral Sciences and the Law, 23(2): 259-276.

Ioimo, R. E. and Aronson, J. E. (2004). Police field mobile computing: Applying the theory of task-technology fit. Police Quarterly, 7(4): 403-428.

Jannetta, J. and Lachman, P. (2011). Promoting Partnerships between Police and Community Supervision Agencies: How Coordination can Reduce Crime and Improve Public Safety. Washington, D.C.: U.S. Department of Justice, Office of Community Orientated Policing Services.

Johnson, I. M. (2007). Victims' perceptions of police response to domestic violence incidents. Journal of Criminal Justice, 35(5): 498-510.

King, N. (1994). The Qualitative Research Interview. In C. Cassell and G. Symon (Eds.), Qualitative Methods in Organizational Research, pp. 14-36. London: Sage.

Lee, J., Zhang, Y., and Hoover, L. T. (2013). Police response to domestic violence: Multilevel factors of arrest decision. Policing: An International Journal of Police Strategies and Management, 36(1): 157-174.

Logan, T. K. and Walker, R. (2004). Separation as a risk factor victims of intimate partner violence: Beyond lethality and injury: A response to Campbell. Journal of Interpersonal Violence, 19(12): 1478-1486. 
Mahoney, M. R. (1991). Legal images of battered women: Redefining the issue of separation. Michigan Law Review, 90(1): 1-94.

McFarlane, J., Campbell, J., Wilt, S., Sachs, C., Ulrich, Y., and Xu, X. (1999). Stalking and intimate partner femicide. Homicide Studies, 3(4): 300-316.

McGarrell, E. F., Zimmerman, C., Hipple, N. K., Corsaro, N., and Perez, H. (2005). The roles of the police in the offender reentry process. International Journal of Comparative and Applied Criminal Justice, 29(1), 53-78.

Messing, J. T., Campbell, J., Wilson, J. S., Brown, S., and Patchell, B. (2015). The Lethality Screen: The predictive validity of an intimate partner violence risk assessment for use by first responders. Journal of Interpersonal Violence. Advanced online publication. DOI: 10.1177/0886260515585540.

Messing, J. T. and Thaller, J. (2013). The average predictive validity of intimate partner violence risk assessment instruments. Journal of Interpersonal Violence, 28(7): 1537-1558.

Murphy, D. (2008). Police-probation partnerships: Managing the risks and maximizing benefits. Justice Policy Journal, 5(1), 4-27.

National Institute of Justice. (2015). How Widespread Is Intimate Partner Violence? Washington DC: U.S. Department of Justice. Retrieved from http://www.nij.gov/topics/crime/intimatepartner-violence/Pages/extent.aspx

Nietzel, M. T. (2000). Police Psychology. In A. Kazdin (Ed.), Encyclopedia of Psychology. Washington, DC: American Psychological Association, 6: 223-226.

Paterson, C. and Clamp, K. (2014). Innovating responses to managing risk: Exploring the potential of a victim-focused policing strategy. Policing: A journal of policy and practice, 8(1), 51-58.

Police Executive Research Forum. (2015). Police improve response to domestic violence, but abuse often remains the 'Hidden Crime'. Subject to Debate, 29(1), 1-11.

Rennison, C. M. (2003). Intimate Partner Violence, 1993-2001. Bureau of Justice Statistics. Washington DC: U.S. Department of Justice. NCJ 197838.

Robinson, A. L. (2006). Reducing repeat victimization among high-risk victims of domestic violence: the benefits of a coordinated community response in Cardiff, Wales. Violence against women, 12(8), 761-788. 
Robinson, A. L., Pinchevsky, G. M., and Guthrie, J. A. (2016). A small constellation: Risk factors informing police perceptions of domestic abuse. Policing and Society. Advanced Online Publication. DOI: 10.1080/10439463.2016.1151881.

Salvemini, A., Piza, E. L., Carter, J. G., Grommon, E., and Merritt, N. (2015). Research challenges in conducting technology evaluations in the criminal justice system: Integrating human factors engineering methods to develop guiding principles and collaborative research processes. Evaluation Review, 39(3), 308-338.

Sherman, L. W. and Berk, R. A. (1984). The Minneapolis Domestic Violence Experiment. Police Foundation Reports. Washington, DC.

Singer, S. I. (1988). The fear of reprisal and the failure of victims to report a personal crime. Journal of Quantitative Criminology, 4(3): 289-302.

Stanley, N., and Humphreys, C. (2014). Multi-agency risk assessment and management for children and families experiencing domestic violence. Children and Youth Services Review, 47(1), 78-85.

Stephens, B. J., and Sinden, P. G. (2000). Victims' voices: Domestic assault victim's perceptions of police demeanor. Journal of Interpersonal Violence, 15(5): 534-547.

Tjaden, P., and Thoennes, N. (2000). Prevalence, incidence, and consequences of violence against women: Findings from the National Violence Against Women Survey. Washington, DC: U.S. Department of Justice, Office of Justice Programs, National Institute of Justice. NCJ 183781.

Townsend, M., Hunt, D., Kuck, S., and Baxter, C. (2006). Law Enforcement Response to Domestic Violence Calls for Service. Final Report. National Institute of Justice. U.S. Department of Justice. Washington, DC. NCJ 215915.

Trujillo, M. P. and Ross, S. (2008). Police response to domestic violence: Making decisions about risk and risk management. Journal of Interpersonal Violence, 23(4): 454-473.

Truman, J. L., and Morgan, R. E. (2014). Nonfatal Domestic Violence, 2003-2012. Bureau of Justice Statistics. Washington DC: U.S. Department of Justice. NCJ 244697.

United Nations. (2010). Handbook on Effective Police Responses to Violence Against Women. United Nations Office on Drugs and Crime. Vienna, Austria. Retrieved from https://www.unodc.org/documents/justice-and-prison- 
reform/Handbook_on_Effective_police_responses_to_violence_against_women_English. pdf.

World Health Organization. (2005). WHO Multi-Country Study on Women's Health and Domestic Violence Against Women: Summary Report of Initial Results on Prevalence, Health Outcomes and Women's Responses. Geneva. Available from http://www.who.int/gender/violence/who_multicountry_study/summary_report/summary _report_English2.pdf 
Figure 1. Communication Pathways Once a GPS Alert is Triggered

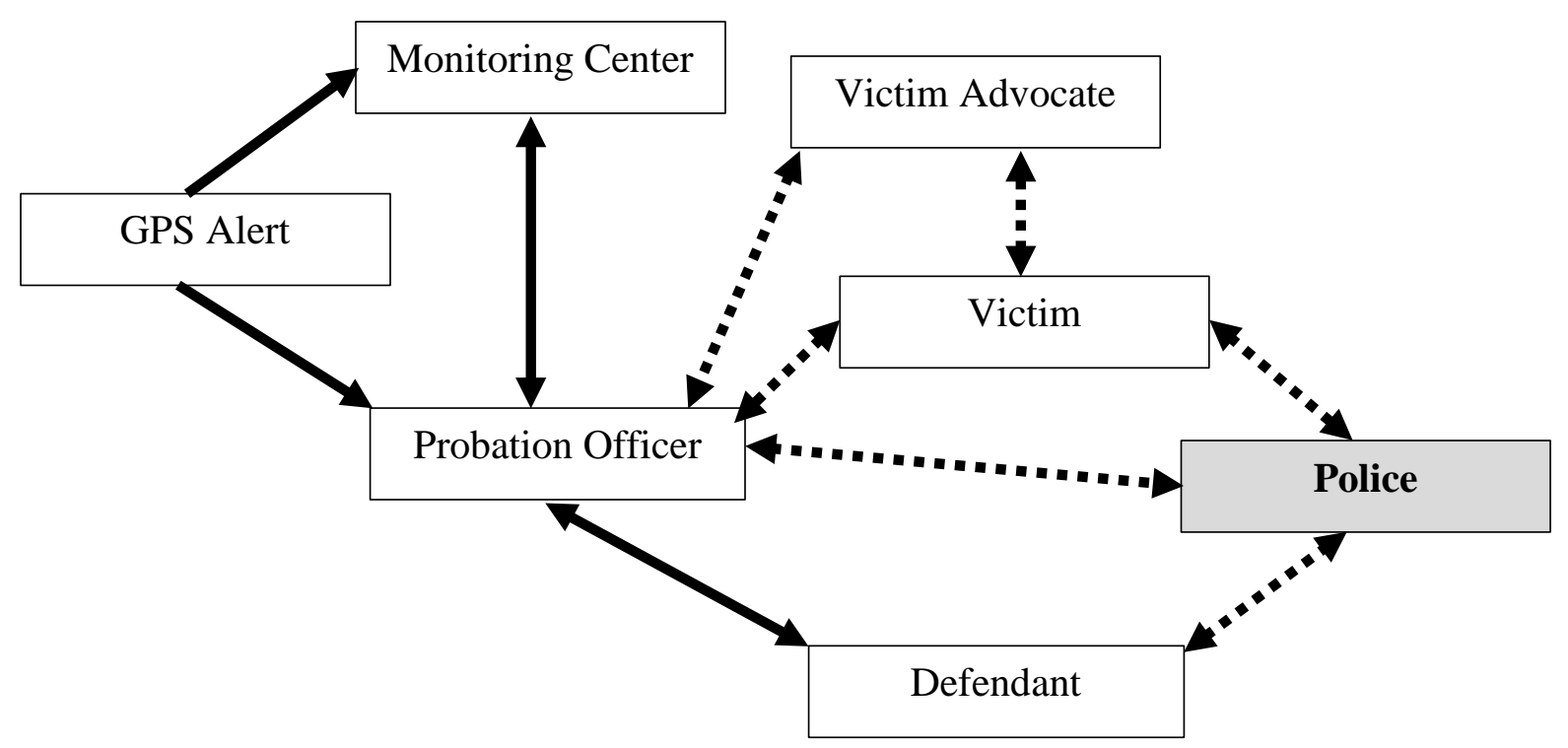

